\title{
Orquiepididimite em carneiro por Salmonella enterica sub-diarizonae: primeiro caso na América do Sul
}

\author{
[Orchiepididymitis in ram by Salmonella enterica sub diarizonae: first case in South America] \\ E.C.C. Celeghini ${ }^{1}$, L. Gregory ${ }^{1}$, E.S. Pinheiro ${ }^{2}$, F.M. Piva ${ }^{1}$, P.A.B. Carneiro ${ }^{1}$, \\ B. Parapinski-Santos ${ }^{1}$, M. Bianchi ${ }^{1}$, F.J. Benesi ${ }^{1}$ \\ ${ }^{1}$ Faculdade de Medicina Veterinária e Zootecnia - Universidade de São Paulo - São Paulo, SP \\ ${ }^{2}$ Instituto Biológico - São Paulo, SP
}

\begin{abstract}
RESUMO
O objetivo deste artigo é relatar um caso de orquiepididimite associado com infecção por Salmonella enterica subespécie diarizonae em carneiro da raça Santa Inês de quatro anos de idade, vasectomizado. Ao exame clínico reprodutivo, o animal mostrou aumento severo do conteúdo escrotal, sendo o testículo direito maior do que o esquerdo e a cauda do epidídimo direita maior do que a esquerda. A consistência testicular, avaliada em escala de 1 a 5 , foi 5 para o testículo direito e 2,5 para o esquerdo; o órgão apresentava-se muito sensível ao toque. $\mathrm{Na}$ ultrassonografia foram observadas estruturas anecoicas/hipoecoicas circulares na cauda do epidídimo, sugestivas de abscessos; alguns pontos hiperecogênicos no parênquima testicular, sugerindo lesões de calcificação; e todo o testículo direito rodeado por imagem hipoecoica, indicativa de edema. Uma das estruturas da cauda do epidídimo direita foi puncionada, encontrando-se exsudato purulento, o qual foi enviado para exame microbiológico, sendo isolada e identificada Salmonella enterica subespécie diarizonae. O carneiro foi submetido a orquiepididectomia, e o órgão foi caracterizado macroscopicamente por adesões fibrosas entre as camadas escrotais, coexistência de abscessos epididimários e degeneração testicular. A Salmonella enterica subespécie diarizonae deve ser considerada no diagnóstico diferencial de infecção genital em ovinos.
\end{abstract}

Palavras-chave: epididimite, orquite, patologia, infecção, ovino

\begin{abstract}
The objective of this manuscript was to report a case of orchiepididymitis associated with Salmonella enterica subespécie diarizonae infection in a vasectomized 4-year-old Santa Inês ram. In the clinicalreproductive examination, the animal showed a severe enlargement of the scrotal contents, being the right testicle larger than left, and the right epididymal cauda was higher than the left. The testicular consistency, evaluated in a scale from 1 to 5 , was 5 to the right and 2.5 to the left, and the organ was very sensitive to the touch. In the ultrasound circular structures anechoic/hypoechoic in the epididymal cauda were observed, and in the parenchyma of testicles some points of hyperechogenic image, suggesting calcification lesions and the entire right testicle was surrounded by hypoechoic image, indicative of edema. One of those structures of the right epididymal cauda was aspirated and a purulent exsudate was found, which was sent to microbiological exam, was isolated and identified Salmonella enterica subespécie diarizonae. The ram was submitted to orchiepididectomy, and the organ was characterized macroscopically by fibrous adhesions between scrotum layers, coexistence of epididymal abscesses and testicular degeneration. The Salmonella enterica subspecie diarizonae must be taken into account in the differential diagnosis of ovine genital infections.
\end{abstract}

Keywords: epididymitis, orchitis, pathology, infection, ovine

Recebido em 22 de março de 2012

Aceito em 19 de dezembro de 2012

E-mail: celeghin@usp.br 


\section{Celeghini et al.}

\section{INTRODUÇÃO}

Em ovinos, o principal e mais frequente agente da orquiepididimite infecciosa é a Brucella ovis (Ná-Rez et al., 1999; Gomes et al., 2001; Carvalho Júnior et al., 2010), seguida pelo Actinobacillus seminis (Ná-Rez et al., 1999; Gomes et al., 2001; Gregory et al., 2009b; Carvalho Júnior et al., 2010), Histophilus somni (Carvalho Júnior et al., 2010) e Corynebacterium pseudotuberculosis (Gregory et al., 2009a). Citase ainda a ocorrência de orquiepididimite por Actinobacillus lignieresii, Corynebacterium pyogenes (Nascimento e Santos, 2003) e Salmonella enterica subspécie diarizonae (Ferreras et al., 2007).

Em Dubois (Idaho/EUA), 79,5\% dos carneiros que apresentavam lesões no epidídimo tinham como causa primária a B. ovis; no mesmo estudo, o A. seminis e o $H$. somni seguiram como as duas mais frequentes causas dessas lesões (Walker et al., 1986).

Em 1999, cerca de $20 \%$ do rebanho de ovinos de três estados mexicanos apresentavam infertilidade ou subfertilidade relacionadas à epididimite causada pela B. ovis, e $9 \%$ do rebanho apresentavam epididimite por $A$. seminis (Ná-Rez et al., 1999).

Em 2009, foi relatado o primeiro caso de ocorrência de orquiepididimite ovina causada por A. seminis no estado de São Paulo (Gregory et al., 2009b); além deste, no Brasil existem apenas mais dois relatos de ocorrência de orquiepididimite em ovinos por A. seminis, sendo os dois no estado do Rio Grande do Sul (Hope et al., 1992; Gomes et al., 2001). A orquiepididimite em carneiros causada por Salmonella enterica subspécie diarizonae foi descrita pela única vez na Espanha (Ferreras et al., 2007).

Apesar de raros relatos na literatura sobre a orquiepididimite causada pela Salmonella spp. em animais (Clark et al., 1992), há, em humanos, isolamento frequente desse patógeno em testículos que apresentem aumento de volume e/ou lesões supurativas (Svenungsson, 1984; Handrick et al., 1987; Berner et al., 1994; AlObeid et al., 2005).
Em humanos, a orquiepididimite causada pela Salmonella spp. pode ou não estar associada com patógenos que ocasionem enterites (Handrick et al., 1987; Berner et al., 1994; Al-Obeid et al., 2005). Cohen et al. (1987) estudaram os sintomas ocasionados pela infecção não entérica por Salmonella spp. em humanos e foi constatado que somente $1,4 \%$ (12/700) dos pacientes apresentava manifestação inflamatória em testículos e epidídimos.

A presença de Salmonella enterica em ovinos é estudada em todo o mundo. Há diversas espécies e subespécies de Salmonella. Na África do Sul, foi realizado estudo recente, indicando que a subespécie mais frequente que acomete os animais neste país é a Salmonella enterica subspécie enterica serovar Typhimurium, sendo a subespécie diarizonae ausente na prevalência do estudo (Kidanemariam et al., 2010). Na Noruega, foi feito o levantamento da prevalência de Salmonella enterica subespécie diarizonae nos rebanhos ovinos, revelando variação de 0 a $45 \%$, sendo os ovinos adultos os mais acometidos pelo agente (Alvseike e Skjerve, 2002).

A prevalência de Salmonella enterica subespécie diarizonae em amígdalas de ovinos coletadas em abatedouro foi de 43\%, mostrando que há animais infectados que são assintomáticos e são fontes de infecção para outros animais (Bonke $e t$ al., 2011). Por outro lado, estudos realizados com camundongos infectados pela Salmonella enterica mostram que estes agentes possuem relativa resistência a antibióticos e migram para novos focos, podendo migrar de um foco inicial no intestino e colonizar novos órgãos, como fígado, testículo e epidídimo (Mastroeni et al., 2009).

Objetivou-se neste trabalho descrever um caso de orquiepedidimite causada por Salmonella enterica subespécie diarizonae em um carneiro da raça Santa Inês.

\section{CASUÍSTICA}

Um ovino de quatro anos de idade, da raça Santa Inês, vasectomizado e utilizado como rufião em uma propriedade, foi atendido no Serviço de Clínica de Bovinos e Pequenos Ruminantes do Hospital Veterinário da Faculdade de Medicina Veterinária e Zootecnia da Universidade de São Paulo (CBPR/HOVET/FMVZ/USP). A queixa 
principal era de que o animal apresentava aumento de volume testicular direito há cinco dias, sendo realizado tratamento prévio com antibiótico (penicilina) por cinco dias, sem sucesso. $\mathrm{O}$ animal estava em serviço até um mês atrás, rufiando as fêmeas (rebanho de 500 ovinos).

Ao exame clínico inicial, não foram observadas alterações nos parâmetros vitais. O escore de condição corporal (ECC) foi classificado como 4, em uma escala de 1 a 5.

Ao exame clínico reprodutivo, os testículos e os epidídimos foram avaliados por palpação quanto à mobilidade, sensibilidade e consistência; ainda foram realizados os exames biométrico e ultrassonográfico dos órgãos.

Os testículos e os epidídimos apresentaram redução da mobilidade intraescrotal, característica de edema local, e mostravam-se muito sensíveis ao toque, em especial os órgãos do lado direito. O testículo direito apresentou consistência de 5,0, e o esquerdo de 2,5, avaliada em escala de 1 a 5 , sendo 1 a consistência mais flácida e 5 a mais firme.

O perímetro escrotal mensurado foi de $42 \mathrm{~cm}$. O testículo direito $(9,8 \times 7,0 \times 7,6 \mathrm{~cm})$ era maior que o esquerdo $(8,2 \times 5,5 \times 6,6 \mathrm{~cm})$. A cauda do epidídimo direito $(7,2 \mathrm{~cm})$ foi maior que a cauda do epidídimo esquerdo $(5,6 \mathrm{~cm})$.

Em seguida, foi realizada a avaliação ultrassonográfica, por meio da qual foram visualizadas estruturas anecoicas e hipoecoicas circulares na cauda do epidídimo, indicativas de abscessos, bem como pontos hiperecogênicos no parênquima testicular, sugerindo lesões de calcificação, e, em torno dos testículos, imagem hipoecoica, sugerindo edema.

Foi realizada aspiração asséptica guiada pelo ultrassom com agulha e seringa estéreis do conteúdo da cauda do epidídimo, onde foram visualizadas as estruturas circulares anecoicas e hipoecoicas. O conteúdo coletado, cerca de $30 \mathrm{~mL}$, apresentava-se com aspecto purulento, confirmando a condição de abscessos, sendo enviado para o exame microbiológico no Laboratório de Doenças Bacterianas da Reprodução do Instituto Biológico de São Paulo, no qual foi feito o isolamento de Salmonella spp.
O soro sanguíneo também foi enviado para o Instituto Biológico de São Paulo para se verificar a existência de Leptospira spp., sendo negativo para o agente. $\mathrm{O}$ animal era não reagente ao teste de tuberculina aviária e bovina.

Após a confirmação do agente causador da orquiepididimite, realizou-se a orquiepididimectomia bilateral para se verificarem as alterações macroscópicas. Foram encontradas aderências fibrosas entre as camadas do escroto, aumento de tamanho do testículo direito, abscessos na cauda do epidídimo (Fig. 1), fibrose, focos de exsudato purulento e degeneração testicular.

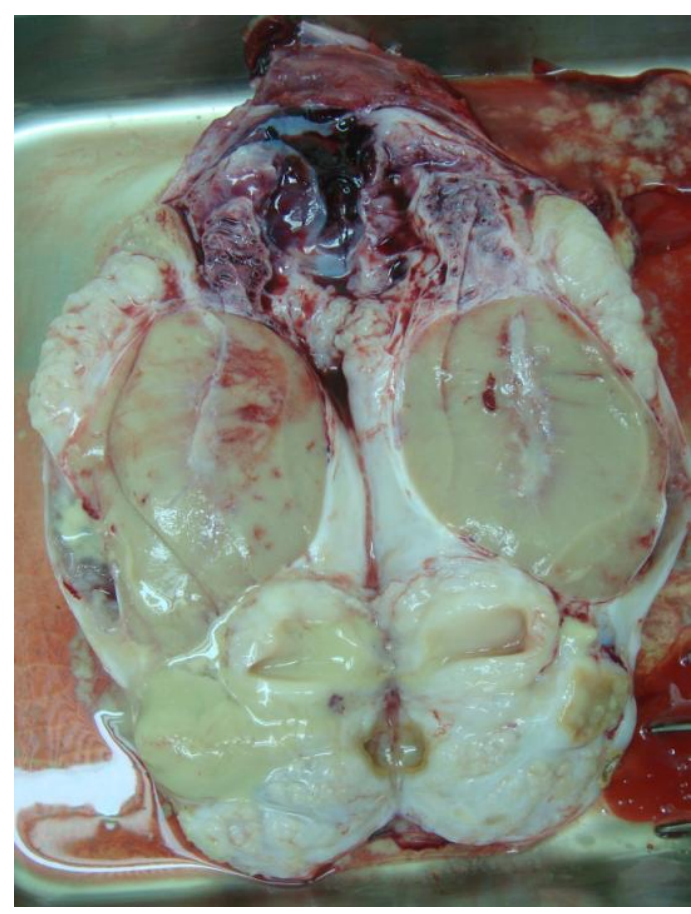

Figura 1. Aspecto macrosópico do testículo direito em corte sagital evidenciando a presença de abscessos no epidídimo do carneiro da raça Santa Inês apresentando orquiepididimite por Salmonella enterica subespécie diarizonae.

Logo após a remoção, os testículos e os epidídimos direitos e esquerdos foram enviados, sob refrigeração, para o Instituto Adolfo Lutz para confirmação do agente causador, excluindose a possibilidade de alguma contaminação na coleta do material ou na manipulação da amostra. $\mathrm{O}$ agente causador foi confirmado como sendo Salmonella spp. e, para a identificação da espécie 
e subespécie, a amostra também foi submetida à técnica de PCR, em que foi identificada a Salmonella enterica subespécie diarizonae.

\section{DISCUSSÃO}

A ocorrência de modificações inflamatórias em testículos e epidídimos determina quadros de subfertilidade, infertilidade ou esterilidade de carneiros (Bicudo et al., 2007; Carvalho Júnior et al., 2010), sendo, então, de grande importância para a produção de ovinos, uma vez que tais alterações irão originar falhas reprodutivas em rebanhos.

O animal atendido na Clínica de Bovinos e Pequenos Ruminantes da USP apresentava inflamação aguda no testículo e no epidídimo direito. $\mathrm{O}$ estado geral do animal não estava alterado, porém esta alteração nem sempre é observada, como foi descrito por Bicudo et al. (2007), em caso de inflamação aguda em testículo e epidídimo. $\mathrm{O}$ testículo direito apresentava consistência firme (5, em uma escala de 1 a 5) e aumento de volume, o que pode ser em decorrência do edema, além da sensibilidade característica do quadro inflamatório. O testículo esquerdo não apresentou alterações de volume, mas a consistência reduzida pode ter ocorrido como consequência de aumento de temperatura local devido ao quadro inflamatório local.

O foco primário de colonização da Salmonella enterica subespécie diarizonae no organismo do carneiro atendido não está elucidado, porém, segundo Mastroeni et al. (2009), a via hematógena é o acesso mais comum para este agente. Uma possibilidade na transmissão deste patógeno, que poderia ser considerada, é em relação ao comportamento homossexual destes animais, com contaminação do pênis por fezes contendo o agente; todavia, Bicudo et al. (2007) afirmaram que infecções testiculares e epididimárias raramente estão associadas a uma via ascendente causada pela uretrite, prostatite ou vesiculite seminal. Segundo Cohen et al. (1987), a orquiepididimite causada pela Salmonella spp. não necessariamente está envolvida com a manifestação gastroentérica que esta bactéria provoca, justificando o fato de o animal atendido não ter tido um histórico de distúrbios gastrointestinais.
O animal atendido não apresentava alterações digestórias, respiratórias, cardiovasculares, locomotoras e/ou neurológicas; somente alterações reprodutivas. Segundo Bonke et al. (2011), a infecção por Salmonella enterica subespécie diarizonae pode ser assintomática, pois $43 \%$ dos ovinos abatidos que continham o agente infeccioso em suas amígdalas não apresentavam qualquer sintoma.

No exame ultrassonográfico do testículo direito, foram visualizadas estruturas anecoicas e hipoecoicas circulares na cauda do epidídimo, indicando a formação de abscessos. A confirmação da presença de abscessos foi feita pela aspiração guiada pelo ultrassom de conteúdo purulento. A ocorrência de tais lesões também foi relatada por Ferreras et al. (2007), que observaram presença de abscessos com exsudato purulento acinzentado em testículo de carneiro acometido pela Salmonella enterica subespécie diarizonae.

$\mathrm{Na}$ análise macroscópica do testículo afetado, foram encontradas aderências fibrosas entre as camadas do escroto, abscessos na cauda do epidídimo, focos de exsudato purulento e fibrose, as mesmas lesões que foram observadas por Ferreras et al. (2007) em animal acometido por Salmonella enterica subespécie diarizonae.

A degeneração testicular observada neste caso diferiu do caso relatado por Ferreras et al. (2007), que não observaram esta alteração. A degeneração testicular pode ter sido decorrente da infecção, como mostra Gouletsou et al. (2004), que induziram a infecção testicular por Arcanobacterium pyogenes e observaram lesões de degeneração testicular.

Outro fato que deve ser levado em consideração é que se trata de um animal vasectomizado, portanto as lesões encontradas podem ser resultantes deste procedimento. Segundo Gouletsou et al. (2008), a vasectomia pode resultar em adesões entre as túnicas vaginais parietal e visceral, o epidídimo pode aumentar de volume e se tornar firme e pode ocorrer a formação de granulomas. Desta forma, algumas alterações observadas podem ter sido decorrentes da vasectomia e não da infecção. 


\section{CONCLUSÃO}

A orquiepididimite infecciosa é causada principalmente pela Brucella ovis. Entretanto, outros agentes bacterianos devem ser considerados como diferenciais, tais como o Actinobacillus seminis, o Histophilus somni e o Corynebacterium pseudotuberculosis. Este relato mostra que a Salmonella enterica subespécie diarizonae também deve ser considerada como diferencial em casos de orquiepididimite.

\section{REFERÊNCIAS}

AL-OBEID, K.; AL KHALIFAN, N.N.; JAMAL, W. et al. Epididymo-Orchitis and testicular abscess caused by Salmonella enteritidis in immunocompromised patients in kuwait. Med. Princ. Pract., v.15, p.305-308, 2005.

ALVSEIKE, O.; SKJERVE, E. Prevalence of a Salmonella subspecies diarizonae in Norwegian sheep herds. Prev. Vet. Med., v.52, p.277-285, 2002.

BERNER, R.; SCHUMACHER, R.F.; ZIMMERHACKL, L.B. Salmonella enteritidis orchitis in a 10-week-old boy. Acta Paediatr., v.83, p.992-993, 1994.

BICUDO, S.D.; SIQUEIRA, J.B.; MEIRA, C. Patologias do sistema reprodutor de touros. Biológico, v.69, p.43-48, 2007.

BONKE, R.; WACHECK, S.; BUMANN, C. et al. High prevalence of Salmonella enterica subsp. diarizonae in tonsils of sheep at slaughter. Food Res. Int., v.45, p.880-884, 2011.

CARVALHO JÚNIOR, C.A.; XAVIER, M.N.; COSTA, L.F. et al. Agentes infecciosos que podem promover infertilidade em machos da espécie ovina. Rev. Bras. Reprod. Anim., v.34, p.160-167, 2010.

CLARK, J.D.; SHOTTS, E.B.J.; HILL, J.E.; MCCALL, J.W. Salmonelosis in gerbils induced by nonrelated experimental procedure. Lab. Anim. Sci., v.42, p.161-163, 1992.

COHEN, J.I.; BARTLETT, J.A.; COREY, G.R. Extra-intestinal manifestations of Salmonella infections. Medicine (Baltimore), v.66, p.349388, 1987.
FERRERAS, M.C.; MUÑOS, M.; PÉREZ, V. et $a l$. Unilateral orchitis and epididymitis caused by Salmonella enterica subspecies diarizonae infection in a ram. J. Vet. Diagn. Invest., v.19, p.194-197, 2007.

GOMES, M.J.P.; DRIEMEIER, D.; BONETTI, A.L. et al. Epididimite ovina: isolamento de Actinobacillus seminis no RS - Brasil. Arq. Fac. Vet., UFRGS, v.29, p.55-58, 2001.

GOULETSOU, P.G.; FTHENAKISA， G.C.; CRIPPSB, P.J. et al. Experimentally induced orchitis associated with Arcanobacterium pyogenes: clinical, ultrasonographic, seminological and pathological features. Theriogenology, v.62, p.1307-1328, 2004.

GOULETSOU, P.G.; GALATOS, A.D.; FTHENAKIS, G.C. Clinical, ultrasonographic and pathological features following unilateral vasectomy in rams. Anim. Reprod. Sci., v.103, p.52-68, 2008.

GREGORY, L.; MELVILLE, P.A.; DUARTE, B.O. et al. Isolamento de Corynebacterium pseudotuberculosis em testículo caprino: Relato de caso. In: CONGRESSO INTERNACIONAL FEINCO, 4., 2009, São Paulo. Anais... São Paulo, 2009a.

GREGORY, L.; RIZZO, H.; MEIRA JUNIOR, E.B.S. et al. Relato do primeiro caso de orquite e epididimite unilateral ovina causada por Actinobacillus seminis no Estado de São Paulo, Brasil. Rev. Bras. Reprod. Anim., v.33, p.105107, 2009b.

HANDRICK, W.; BERGMANN, L.; SPENCKER, F.B.; BENNEK, J. Orchitis and epididymitis caused by Salmonella cholerae suis in a premature infant. Z. Urol. Nephrol., v.80, p.8991, 1987.

HOPE, L.P.; LAITANO, J.L.L.; FERNANDES, R.E. Epididimite ovina: Isolamento de Actinobacillus seminis em Central de Inseminação artificial no Rio Grande do Sul. In: CONGRESSO ESTADUAL DE MEDICINA VETERINÁRIA, 11., 1992, Gramado. Anais..., Gramado: CEMV, 1992. p.96.

KIDANEMARIAM，A.; ENGELBRECHT, M.; PICARD, J. Retrospective study on the incidence of Salmonella isolations in animals in South Africa: 1996 to 2006. J. S. Afr. Vet. Assoc., v.81, p.37-44, 2010. 


\section{Celeghini et al.}

MASTROENI, P.; GRANT, A.; RESTIF, O.; MASKELL, D. A dynamic view of the spread and intracellular distribution of Salmonella enterica. Nature Rev. Microbiol., v.7, p.73-80, 2009.

NÁ-REZ, G.M.; APARICIO, E.D.; ÁLVAREZ, J.F.M. et al. Epidimitis ovina: Estudios bacteriológico y serológico. Vet. Mex., v.30, p.329-336, 1999.
NASCIMENTO, E.F.; SANTOS, R.L. Patologia da reprodução dos animais domésticos. Rio de Janeiro: Guanabara-Koogan, 2003. 137p.

SVENUNGSSON, B. Suppurative epididymoorchitis due to Salmonella enteritidis. J. Infect. Dis., v.8, p.64-66, 1984.

WALKER, R.L.; LEAMASTER, B.R.; STELLFLUG, J.N.; BIBERSTEIN, E.L. Association of age of ram with distribution of epididymal lesions and etiologic agent. J. Am. Vet. Med. Assoc., v.188, p.25-34, 1986. 